\title{
Diffuse large B-cell lymphoma of the breast: prognostic factors and treatment outcomes
}

\author{
This article was published in the following Dove Press journal: \\ OncoTargets and Therapy \\ 6 April 2016 \\ Number of times this article has been viewed
}

Yao Sun'
Monika Joks²
Li-Ming Xu'
Xiu-Li Chen'
Dong Qian'
Jin-Qiang You'
Zhi-Yong Yuan'

'Department of Radiation Oncology, CyberKnife Center, Key Laboratory of Cancer Prevention and Therapy, Tianjin Medical University Cancer Institute and Hospital, National Clinical Research Center for Cancer Tianjin, People's Republic of China; ${ }^{2}$ Department of Hematology and Bone Marrow Transplantation, Poznan University of Medical Science, Poznan, Poland

Correspondence: Zhi-Yong Yuan Department of Radiation Oncology, CyberKnife Center, Tianjin Medical University Cancer Institute and Hospital, Huan-Hu-Xi Road, Ti-Yuan-Bei, He Xi District, Tianjin 300060, People's Republic of China

Email zhiyong0524@I63.com
Background: The breast is a rare site of extranodal involvement of diffuse large B-cell lymphoma (DLBCL). We aimed to assess the clinical characteristics, prognostic factors, and treatment outcomes of breast DLBCL.

Patients and methods: We retrospectively analyzed 113 patients (from our institution and the literature) between 1973 and 2014. The primary end point was overall survival (OS). KaplanMeier OS curves were compared with the log-rank test. Cox regression analysis was applied to determine the prognostic factors for OS, progression-free survival (PFS), local control (LC), and cause-specific survival (CSS).

Results: A total of 113 patients were included in the study: 42 cases from our hospital and 71 cases from 12 publications. The median age at diagnosis was 58 years. With a median follow-up time of 39.2 months, the estimated 5-year OS, PFS, LC, and CSS were 71.4\%, $58.8 \%$, $75.6 \%$, and $74.9 \%$, respectively. In multivariate analysis, more than four cycles of chemotherapy, having localized cancer, lumpectomy with or without axillary lymph node (ALN) dissection, and low to low-to-intermediate International Prognostic Index were favorable factors for OS. For PFS, significant prognostic factors were rituximab use, B symptoms, and tumor size. As for the local group, lumpectomy with or without ALN dissection and more than four cycles of chemotherapy were favorable factors for OS. Tumor size $>4 \mathrm{~cm}$ and nonuse of rituximab were adverse factors for PFS. Twenty-one patients (18.6\%) developed local relapse and 33 (29.2\%) developed systemic relapse. Eight patients had central nervous system relapse (7.3\%).

Conclusion: Our results reveal that local and extended staging criteria can reflect the different prognosis and treatment outcomes of breast DLBCL. Rituximab use, lumpectomy, and more than four cycles of chemotherapy are recommended as a treatment regimen. However, further study is warranted to validate our data.

Keywords: diffuse large B-cell lymphoma, breast, rituximab, surgery, chemotherapy

\section{Introduction}

Breast lymphoma is a rare form of extranodal lymphoma. It constitutes $0.5 \%$ of breast malignancies, $1 \%$ of non-Hodgkin lymphoma (NHL), and $3 \%$ of extranodal lymphoma. The predominant histopathology is diffuse large B-cell lymphoma (DLBCL). ${ }^{1,2}$ Breast lymphoma can be subdivided into primary breast lymphoma (PBL) and secondary breast lymphoma (SBL). In PBL, the breast is the only site of lymphoma with or without regional lymph node involvement. SBL refers to the presentation of lymphoma in the lymph node region and organs other than the breast and regional lymph nodes. ${ }^{3}$

Currently, there is controversy about the staging of breast lymphoma as PBL or SBL. The definition of PBL was first proposed by Wiseman and Liao ${ }^{3}$ in 1972 in a study that included just 31 patients. This is an extremely small sample from which to draw a conclusion for staging criteria. Because of the rarity of the disease, most 
of the previous studies were small retrospective analyses. There was only one prospective study. ${ }^{4}$ There were wide variations in conclusions about the prognosis and outcome of breast lymphoma.

The treatment of breast lymphoma includes surgery, radiotherapy (RT), and chemotherapy. These have been used alone or in combinations of two or three modalities. However, no consensus has been reached for the best therapy regimen for breast lymphoma. The largest retrospective analysis found that mastectomy provides no survival benefit compared to lumpectomy or biopsy. ${ }^{5}$ Furthermore, the one prospective study revealed that combined therapy with RT and chemotherapy was the best treatment, giving a significant improvement for event-free survival (EFS) and overall survival (OS) compared to single treatment. ${ }^{4}$ These, however, were all studies based on old therapy regimens from the prerituximab era. At present, rituximab has been used widely in nodal DLBCL. The best treatment regimen for breast DLBCL in the rituximab era remains unknown.

This study aims to clarify the issue of prognosis, optimal treatment regimen, and treatment outcome for breast DLBCL now that we have rituximab as a treatment option.

\section{Patients and methods}

\section{Study design and patient eligibility}

The sample included patients with breast lymphoma recruited from our hospital and data extracted from the literature. Patients with a confirmed histopathological diagnosis of breast DLBCL were included. The exclusion criteria were as follows: 1) diagnosis of breast lymphoma other than DLBCL (eg, mucosa-associated lymphoid tissue type lymphoma or follicular lymphoma); 2) uncontrolled comorbidity (metabolic or psychiatric); 3) unrecorded survival time. Initial staging procedures included the following: a complete blood count, chemistry, mammography, breast sonography, bone marrow aspiration and biopsy, and computed tomography of the thorax, abdomen, and pelvis. Fluorodeoxyglucosepositron emission tomography and computed tomography was optional and has been performed since 2005 for staging. According to the Ann Arbor staging criteria, the patients were divided into PBL and SBL. Only bilateral breast involvement was grouped as PBL $\mathrm{IV}_{\mathrm{E}}$. According to the number of involved organs, the patients were divided into one extranodal disease group (OED, the only involvement of breast with or without nodal disease) and multiple extranodal disease group (MED, multiple extranodal organ involvement including breasts, regardless of nodal status). ${ }^{6}$ According to the extent of disease, the patients were classified into local group $\left(\mathrm{PBL} \mathrm{I}_{\mathrm{E}}\right.$ and $\mathrm{II}_{\mathrm{E}}$ ) and extended group (PBL $\mathrm{IV}_{\mathrm{E}}$ and SBL).
The study protocol was in accordance with the ethical guidelines of the Declaration of Helsinki and was approved by the independent ethics committees of Tianjin Medical University Cancer Institute and Hospital. Written informed consent was obtained from all patients in the study.

\section{Literature search and data extraction}

We searched Medline for patients with breast DLBCL between April 1966 and June 2015. The search terms included the word "breast" combined with "DLBCL". For the shortlisted studies, we contacted all principal researchers through email for obtaining detailed information about the patient. A flowchart of patient selection from the literature is shown in Figure 1. The included studies from literature are summarized in Table 1.

\section{Treatment schedule}

Surgical interventions consisted of biopsy, lumpectomy with or without axillary lymph node (ALN) dissection, and mastectomy with or without ALN dissection. RT was administered with conventional fields (tangent beams) or three-dimensional conformal RT for whole breast irradiation. Conventional photon and electron beams were planned for postmastectomy RT. Data were gathered about the chemotherapy agents used and number of cycles. Most of the patients (98.2\%) received anthracycline-based CHOP (cyclophosphamide, doxorubicin, vincristine, prednisone)-like chemotherapy.

\section{Measurements of outcomes and end points}

The primary outcome was OS. The secondary outcomes included progression-free survival (PFS), local control (LC), and cause-specific survival (CSS). All the outcomes were calculated from the date of histopathological diagnosis to the following points: OS (to the date of death), PFS (to the date of progression), LC (to the date of local failure), and CSS (to the date of death from disease or treatment-related causes).

\section{Statistical analysis}

The categorical variables were summarized as frequencies and percentages, while median and range were calculated for continuous variables. The curves for PFS, OS, LC, and CSS were plotted using the Kaplan-Meier method, and comparisons between groups were calculated using log-rank tests. ${ }^{7}$ Multivariate analysis was estimated using Cox proportional hazard models. ${ }^{8} P$-values of $<0.05$ were considered to be statistically significant. SPSS PASW Statistics Version 18.0 for Windows (SPSS Inc., Chicago, IL, USA) was used for statistical analysis. 


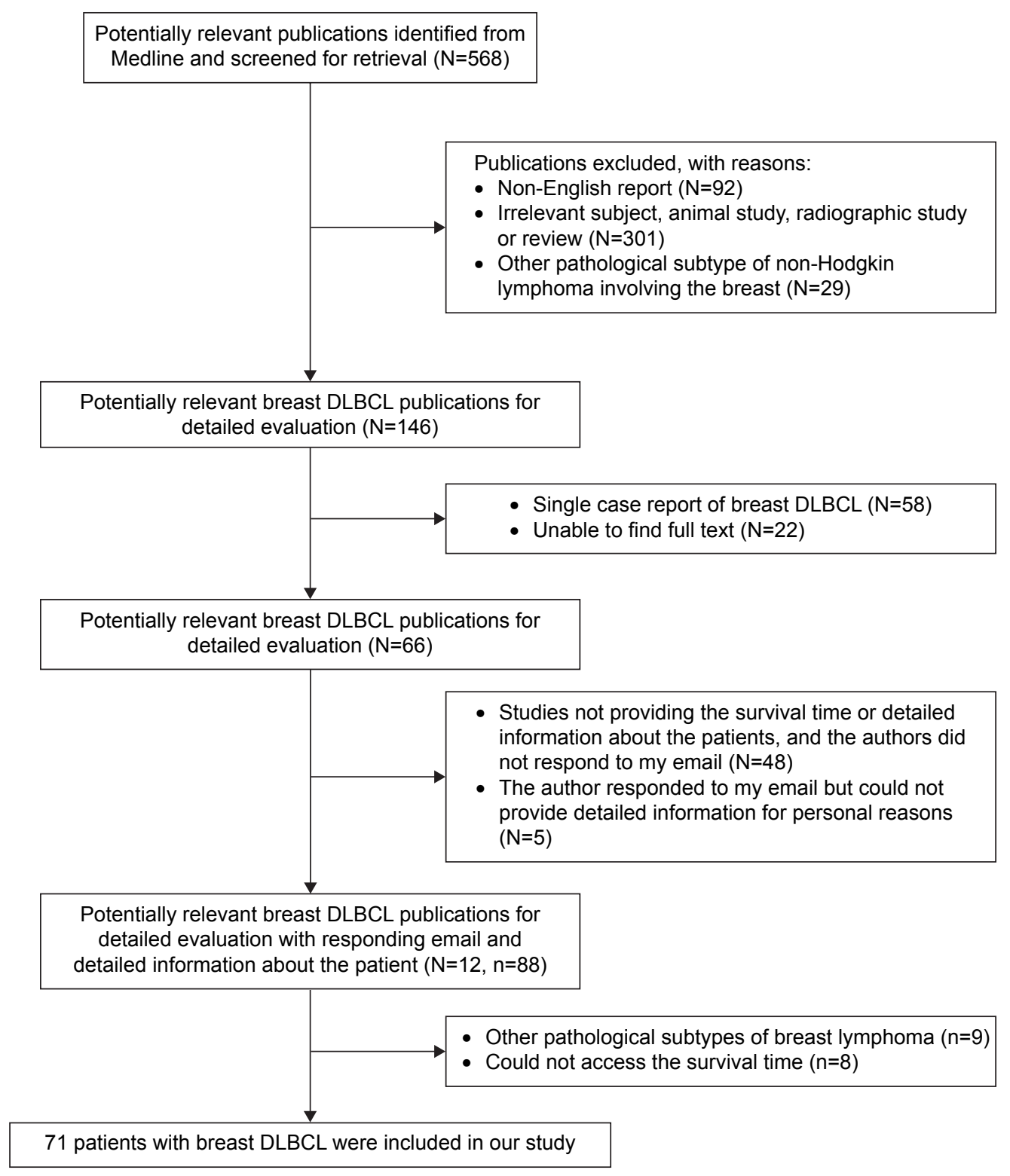

Figure I Flowchart of patient selection from literatures.

Abbreviations: N, number of studies; n, number of patients; DLBCL, diffuse large B-cell lymphoma.

Table I The included studies from literature

\begin{tabular}{|c|c|c|}
\hline Study & $\begin{array}{l}\text { Number of } \\
\text { patients }\end{array}$ & $\begin{array}{l}\text { Country of } \\
\text { origin }\end{array}$ \\
\hline Duan et $a^{31}$ & 11 & $\begin{array}{l}\text { People's Republic } \\
\text { of China }\end{array}$ \\
\hline $\operatorname{lnic}$ et $\mathrm{a}^{32}$ & 3 & Serbia \\
\hline Jung et $\mathrm{al}^{33}$ & 8 & Korea \\
\hline Mouna et $\mathrm{a}^{34}$ & 5 & Morocco \\
\hline Joks et $\mathrm{al}^{35}$ & 2 & Poland \\
\hline Julen et $\mathrm{a}^{36}$ & 5 & Switzerland \\
\hline Sanguinetti et $\mathrm{al}^{37}$ & I & Italy \\
\hline Cabras et a $\left.\right|^{38}$ & 8 & Italy \\
\hline Yoshida et $\mathrm{al}^{39}$ & 15 & Japan \\
\hline Seker et a ${ }^{40}$ & 9 & Turkey \\
\hline Ogawa et $\mathrm{al}^{41}$ & 3 & Japan \\
\hline $\begin{array}{l}\text { Romero- } \\
\text { Guadarrama et al }{ }^{42}\end{array}$ & $\begin{array}{l}\text { Total } 5 \text {, } \\
\text { included I }\end{array}$ & Mexico \\
\hline
\end{tabular}

\section{Results}

\section{Patient characteristics}

A total of 113 patients were included in the analysis: 42 cases (37\%) from our hospital and 71 cases (63\%) from 12 publications. The baseline characteristics of the patients are shown in Table 2. The median age at diagnosis was 58 years (range: 20-89 years old). Of these patients, 108 were female $(95.6 \%)$ and five patients were male (4.4\%). The median tumor size was $4 \mathrm{~cm}$ (range: $2-15 \mathrm{~cm}$ ). Three patients were found to have breast DLBCL during pregnancy. The Eastern Cooperative Oncology Group (ECOG) performance status was 0 or 1 in 102 patients $(90.3 \%)$. B symptoms were present in eight patients (7.1\%). Both breasts were involved in 
Table 2 Patient characteristics

\begin{tabular}{|c|c|c|}
\hline Characteristics & $\mathbf{N}$ & $\%$ \\
\hline \multicolumn{3}{|l|}{ Sex } \\
\hline Male & 5 & 4.4 \\
\hline Female & 108 & 95.6 \\
\hline \multicolumn{3}{|l|}{ Age at diagnosis } \\
\hline$<60$ years & 60 & 53.1 \\
\hline$\geq 60$ years & 53 & 46.9 \\
\hline \multicolumn{3}{|l|}{ Pregnancy at diagnosis } \\
\hline Yes & 3 & 2.7 \\
\hline No & 110 & 97.3 \\
\hline \multicolumn{3}{|c|}{ ECOG performance status } \\
\hline $0-1$ & 102 & 90.3 \\
\hline $2-4$ & II & 9.7 \\
\hline \multicolumn{3}{|l|}{ LDH } \\
\hline Normal & 78 & 69.0 \\
\hline Elevated & 35 & 31.0 \\
\hline \multicolumn{3}{|l|}{ B symptoms } \\
\hline Yes & 8 & 7.1 \\
\hline No & 105 & 92.9 \\
\hline \multicolumn{3}{|l|}{ Primary site } \\
\hline Left & 60 & 53.1 \\
\hline Right & 48 & 42.5 \\
\hline Bilateral & 5 & 4.4 \\
\hline \multicolumn{3}{|l|}{ Tumor size } \\
\hline$\leq 4 \mathrm{~cm}$ & 59 & 52.2 \\
\hline$>4 \mathrm{~cm}$ & 54 & 47.8 \\
\hline \multicolumn{3}{|l|}{ IPI } \\
\hline Low & 83 & 73.5 \\
\hline Low intermediate & 21 & 18.6 \\
\hline High intermediate & 4 & 3.5 \\
\hline High & 5 & 4.4 \\
\hline \multicolumn{3}{|l|}{ Ann Arbor staging } \\
\hline PBL stage $I_{E}$ & 64 & 56.6 \\
\hline PBL stage $I_{E}$ & 37 & 32.7 \\
\hline PBL stage IV & 3 & 2.7 \\
\hline SBL & 9 & 8.0 \\
\hline \multicolumn{3}{|l|}{ OED/MED staging } \\
\hline OED & 104 & 92.0 \\
\hline MED & 9 & 8.0 \\
\hline \multicolumn{3}{|l|}{ Local/extended staging } \\
\hline Local & 101 & 89.4 \\
\hline Extended & 12 & 10.6 \\
\hline
\end{tabular}

Abbreviations: ECOG, Eastern Cooperative Oncology Group; LDH, lactate dehydrogenase; IPI, International Prognostic Index; PBL, primary breast lymphoma; SBL, secondary breast lymphoma; OED, one extranodal disease; MED, multiple extranodal disease.

five patients (4.4\%). All the patients were pathologically confirmed as having breast DLBCL. Sixty-four patients were stage PBL $I_{E}, 37$ were stage PBL II $I_{E}$, three patients were stage PBL IV $\mathrm{E}_{\mathrm{E}}$, and nine patients were stage $\mathrm{SBL}$ - according to the Ann Arbor staging criteria. A total of 104 patients (92.0\%) were classified as having low to low-to-intermediate risk according to International Prognostic Index (IPI) scores.

\section{Treatment and outcome}

The first-line treatment is presented in Table 3. Surgery consisted of lumpectomy and mastectomy with or
Table 3 First-line therapy

\begin{tabular}{|c|c|c|}
\hline Therapy & $\mathbf{N}$ & $\%$ \\
\hline \multicolumn{3}{|l|}{$S(n=77)$} \\
\hline Lumpectomy $\pm \mathrm{ALN}$ dissection & 37 & 48.7 \\
\hline Mastectomy $\pm \mathrm{ALN}$ dissection & 40 & 51.3 \\
\hline \multicolumn{3}{|l|}{$\mathrm{CT}$} \\
\hline Yes & 110 & 97.3 \\
\hline No & 3 & 2.7 \\
\hline \multicolumn{3}{|l|}{ Rituximab use } \\
\hline Yes & 37 & 33.6 \\
\hline No & 73 & 66.4 \\
\hline \multicolumn{3}{|l|}{ CT cycles } \\
\hline$<4$ & 29 & 25.7 \\
\hline$\geq 4$ & 81 & 71.7 \\
\hline No & 78 & 69.9 \\
\hline Yes & 35 & 30.1 \\
\hline \multicolumn{3}{|l|}{ RT fields $(n=35)$} \\
\hline Involved breast and regional LN & 15 & 42.8 \\
\hline Regional LN & I & 2.8 \\
\hline Involved breast only & 11 & 31.4 \\
\hline Chest wall only & 1 & 2.8 \\
\hline Chest wall and regional $\mathrm{LN}$ & 1 & 2.8 \\
\hline Unknown & 6 & 17.4 \\
\hline \multicolumn{3}{|l|}{ RT dose $(n=35)$} \\
\hline Median & $48.6 \mathrm{~Gy}$ & \\
\hline Range & 30-50 Gy & \\
\hline $30-40$ Gy & 9 & 25.7 \\
\hline $4 I-50 \mathrm{~Gy}$ & 15 & 42.8 \\
\hline Unknown & 11 & 31.5 \\
\hline
\end{tabular}

Abbreviations: S, surgery; ALN, axillary lymph node; CT, chemotherapy; RT, radiotherapy; LN, lymph node.

without axillary dissection. Biopsy was not included. Of the 113 patients, surgery was performed on $69 \%$ of the patients. Systemic chemotherapy was administered to $97.3 \%$ of the patients, and $98.2 \%$ of regimens included anthracycline. Of the patients undergoing chemotherapy, $33.6 \%$ received rituximab. RT was performed on $30.1 \%$ of the patients, and the involved breast and regional lymph node was the most common RT field. Four patients received intrathecal chemotherapy as central nervous system (CNS) prophylaxis.

With a median follow-up at 39.2 months (range: 0.5-198 months), the median OS was 144 months, and the estimated 5-year and 10-year OS rates were $71.4 \% \pm 5.0 \%$ and $55.7 \% \pm 7.6 \%$, respectively. The median PFS was not reached at the time of analysis, and the estimated 5-year and 10 -year PFS rates were $58.8 \% \pm 5.6 \%$ and $51.4 \% \pm 6.9 \%$, respectively. The median CSS was also not reached, with 5 -year and 10-year CSS rates being $74.9 \% \pm 4.6 \%$ and $62.9 \% \pm 6.8 \%$, respectively. The 5 -year and 10 -year LC rates were $75.6 \% \pm 4.9 \%$ and $71.6 \% \pm 6.0 \%$, respectively. There were 39 progression events and 32 deaths during the 
follow-up time, with 29 deaths attributed to the disease and treatment-related toxicity.

Following treatment, 21 of 113 patients (18.6\%) developed local relapse. The most common local relapse site was the contralateral breast $(n=9,42.9 \%$ of the patients with locoregional recurrence). Seven patients developed ipsilateral relapse with or without ALN metastasis within 4 years. The other local relapse sites were as follows: bilateral breast with or without ALN metastasis ( $\mathrm{n}=2)$, regional lymph node alone $(\mathrm{n}=2)$, and ipsilateral chest wall $(\mathrm{n}=1)$. RT substantially decreased the risk of ipsilateral progression (hazard ratio [HR] of RT:no RT $=0.470 ; P=0.340$ ).

Thirty-three patients (27.4\%) developed distant metastasis following first-line therapy, with eight patients having more than two metastatic sites at first progression. The distant metastatic sites were as follows: distant lymph node $(\mathrm{n}=16)$, CNS $(n=8)$, bone $(n=9)$, lung $(n=3)$, liver and spleen $(n=2$ for each site), orbit, maxillary sinus, bladder and uterine cervix $(\mathrm{n}=1$ for each site), and sites unknown $(\mathrm{n}=4)$. Eight patients had CNS relapse (7.1\% of all patients). Of the four patients who received intrathecal prophylaxis, none developed CNS relapse.

\section{Prognostic factors}

Univariate analysis of factors influencing OS, PFS, LC, and CSS is presented in Table 4. In univariate analysis, primary tumor size larger than $4 \mathrm{~cm}$, less than four cycles of chemotherapy, and presentation of B symptoms were adverse prognostic factors for all outcome measures. The ECOG performance status, Ann Arbor staging, IPI, lactate

Table 4 Univariate analysis (log-rank test)

\begin{tabular}{|c|c|c|c|c|c|c|c|c|c|}
\hline Variables & $\mathbf{n}$ & $5 y$ OS & $P$-value & 5y PFS & $P$-value & $5 y$ LC & $P$-value & 5y CSS & $P$-value \\
\hline All patients & 113 & 0.714 & & 0.588 & & 0.756 & & 0.749 & \\
\hline \multicolumn{10}{|l|}{ Sex } \\
\hline Male & 5 & 0.400 & 0.594 & 0.267 & 0.254 & 0.533 & 0.300 & 0.400 & 0.476 \\
\hline Female & 108 & 0.730 & & 0.603 & & 0.767 & & 0.767 & \\
\hline \multicolumn{10}{|l|}{$\mathrm{LDH}$} \\
\hline Normal & 78 & 0.756 & 0.016 & 0.657 & 0.007 & 0.802 & 0.107 & 0.810 & 0.012 \\
\hline Elevated & 35 & 0.599 & & 0.405 & & 0.637 & & 0.599 & \\
\hline \multicolumn{10}{|l|}{ Age, years } \\
\hline$<60$ & 60 & 0.725 & 0.719 & 0.593 & 0.650 & 0.753 & 0.499 & 0.749 & 0.474 \\
\hline$\geq 60$ & 53 & 0.688 & & 0.586 & & 0.767 & & 0.745 & \\
\hline \multicolumn{10}{|c|}{ ECOG performance status } \\
\hline $0-1$ & 102 & 0.755 & $<0.001$ & 0.616 & 0.027 & 0.750 & 0.686 & 0.794 & $<0.001$ \\
\hline $2-4$ & II & 0.364 & & 0.284 & & 0.875 & & 0.364 & \\
\hline \multicolumn{10}{|l|}{ B symptoms } \\
\hline Yes & 105 & 0.742 & $<0.001$ & 0.610 & $<0.00 \mathrm{I}$ & 0.773 & 0.019 & 0.780 & $<0.001$ \\
\hline No & 8 & 0.333 & & 0.292 & & 0.525 & & 0.333 & \\
\hline \multicolumn{10}{|l|}{ Primary site } \\
\hline Left breast & 60 & 0.680 & $<0.001$ & 0.582 & 0.072 & 0.795 & 0.675 & 0.756 & $<0.001$ \\
\hline Right breast & 48 & 0.805 & & 0.614 & & 0.713 & & 0.805 & \\
\hline Bilateral & 5 & 0.200 & & 0.267 & & 0.667 & & 0.179 & \\
\hline \multicolumn{10}{|l|}{ Primary tumor size } \\
\hline$\leq 4 \mathrm{~cm}$ & 59 & 0.767 & 0.008 & 0.713 & 0.001 & 0.851 & 0.009 & 0.838 & 0.004 \\
\hline$>4 \mathrm{~cm}$ & 54 & 0.642 & & 0.432 & & 0.661 & & 0.642 & \\
\hline \multicolumn{10}{|l|}{ IPI } \\
\hline Low & 83 & 0.750 & $<0.001$ & 0.608 & 0.011 & 0.767 & 0.765 & 0.795 & $<0.001$ \\
\hline Low intermediate & 21 & 0.749 & & 0.529 & & 0.680 & & 0.749 & \\
\hline High intermediate & 4 & 0.500 & & 0.750 & & & & 0.500 & \\
\hline High & 5 & 0.200 & & 0.267 & & & & 0.200 & \\
\hline \multicolumn{10}{|l|}{ Ann Arbor staging } \\
\hline$P B L I_{E}$ & 64 & 0.769 & $<0.00$ I & 0.589 & $<0.001$ & 0.776 & 0.482 & 0.805 & $<0.001$ \\
\hline$P B L I I_{E}$ & 37 & 0.713 & & 0.675 & & 0.740 & & 0.836 & \\
\hline PBL IV & 3 & 0 & & 0.000 & & 0.500 & & 0.000 & \\
\hline $\mathrm{SBL}$ & 9 & 0.333 & & 0.469 & & 0.667 & & 0.333 & \\
\hline \multicolumn{10}{|l|}{ OED/MED staging } \\
\hline OED & 104 & 0.738 & 0.016 & 0.597 & 0.389 & 0.749 & 0.211 & 0.776 & 0.010 \\
\hline MED & 9 & 0.444 & & 0.469 & & & & 0.444 & \\
\hline
\end{tabular}


Table 4 (Continued)

\begin{tabular}{|c|c|c|c|c|c|c|c|c|c|}
\hline Variables & $n$ & $5 y$ OS & $P$-value & 5y PFS & $P$-value & $5 y$ LC & $P$-value & 5y CSS & $P$-value \\
\hline \multicolumn{10}{|c|}{ Local/extended staging } \\
\hline Local & 101 & 0.776 & $<0.001$ & 0.616 & 0.015 & 0.763 & 0.798 & 0.817 & $<0.001$ \\
\hline Extended & 12 & 0.250 & & 0.344 & & 0.643 & & 0.250 & \\
\hline \multicolumn{10}{|c|}{ Lumpectomy \pm ALN dissection } \\
\hline Yes & 37 & 0.972 & 0.001 & 0.728 & 0.023 & 0.853 & 0.060 & 0.972 & 0.002 \\
\hline No & 76 & 0.593 & & 0.520 & & 0.704 & & 0.645 & \\
\hline \multicolumn{10}{|l|}{ Rituximab use } \\
\hline Yes & 37 & 0.788 & 0.059 & 0.826 & 0.004 & 0.918 & 0.010 & 0.867 & 0.038 \\
\hline No & 73 & 0.674 & & 0.479 & & 0.688 & & 0.696 & \\
\hline \multicolumn{10}{|c|}{ Local radiotherapy } \\
\hline Yes & 35 & 0.786 & 0.302 & 0.676 & 0.192 & 0.770 & 0.772 & 0.830 & 0.277 \\
\hline No & 78 & 0.685 & & 0.548 & & 0.738 & & 0.714 & \\
\hline \multicolumn{10}{|c|}{ Cycles of chemotherapy } \\
\hline$<4$ cycles & 29 & 0.434 & $<0.001$ & 0.408 & 0.017 & 0.492 & 0.001 & 0.434 & $<0.001$ \\
\hline$\geq 4$ cycles & 81 & 0.818 & & 0.651 & & 0.840 & & 0.865 & \\
\hline
\end{tabular}

Abbreviations: OS, overall survival; PFS, progression-free survival; LC, local control; CSS, cause-specific survival; LDH, lactate dehydrogenase; ECOG, Eastern Cooperative Oncology Group; IPI, International Prognostic Index; PBL, primary breast lymphoma; SBL, secondary breast lymphoma; OED, one extranodal disease; MED, multiple extranodal disease; ALN, axillary lymph node.

dehydrogenase (LDH) level, local/extended staging criteria, and lumpectomy with or without ALN dissection were prognostic factors for OS, PFS, and CSS. Rituximab was a favorable factor for PFS, LC, and CSS. Bilaterality and multiple extranodal diseases were adverse prognostic factors for both OS and CSS.

The multivariate analysis for all the treatment outcome measurements is presented in Table 5. The prognostic factors that retained statistical significance for OS and CSS were cycles of chemotherapy and local/extended staging criteria. Lumpectomy with or without ALN dissection and low to low-to-intermediate IPI were favorable factors for OS. Tumor size $>4 \mathrm{~cm}$ and ECOG performance status 2-4 were adverse prognostic factors for CSS. For PFS, the prognostic factors included rituximab use, B symptoms, and tumor size. For LC, fewer than four cycles of chemotherapy, tumor size $>4 \mathrm{~cm}$, and nonuse of rituximab were adverse prognostic factors. The factors that lost statistical significance in multivariate analysis were Ann Arbor stage, OED/MED stage, primary site, and LDH level.

The univariate analysis of local group $\left(\mathrm{PBL} \mathrm{I}_{\mathrm{E}}\right.$ and $\left.\mathrm{II}_{\mathrm{E}}\right)$ is presented in Table 6. Fewer than four cycles of chemotherapy significantly correlated with a worse 5-year OS rate, as is shown in Figure 2A (5-year OS: $59.5 \%$ vs $84.2 \% ; P=0.015$ ). The patients who received rituximab had a significantly superior 5-year PFS compared with patients without rituximab (5-year PFS: 84.3\% vs 50.6\%; $P=0.007$; Figure $2 \mathrm{~B}$ ). Patients with lumpectomy with or without ALN dissection had significantly better 5-year OS compared with the patients without lumpectomy with or without ALN dissection (5-year
OS: $96.3 \%$ vs $68.9 \% ; P=0.003$; Figure $2 \mathrm{C}$ ). However, we found that RT was not associated with significant improvements of OS and PFS, and these findings are presented in Figure 2D. The multivariate analysis is presented in Table 7. Lumpectomy with or without ALN dissection and more than four cycles of chemotherapy were favorable factors for OS. Tumor size $>4 \mathrm{~cm}$ and nonuse of rituximab were adverse factors for PFS.

\section{Discussion}

Breast lymphoma is a distinct clinicopathological entity of NHL, with DLBCL being the most common subtype. The recommended treatment regimen based on many retrospective studies included limited surgery, anthracycline-based chemotherapy, and local RT for PBL. Despite the aggressive treatments being employed, the prognosis for PBL is poor, with 5-year OS rates only between $50 \%$ and $75 \%$. ${ }^{1,9}$ In our study, even though patients with PBL IV $\mathrm{E}_{\mathrm{E}}$ and SBL were included, the 5-year OS was $71.4 \%$, which is not less than that for nodal DLBCL. ${ }^{10,11}$ The better outcome may be attributed to the fact that the IPI scores of most our patients $(92 \%)$ were $<2$, and 37 patients received rituximab in addition to the standard chemotherapy.

Because of the rarity of breast lymphoma, most of the studies have been retrospective, and there has been only one controlled randomized prospective study. ${ }^{4}$ The retrospective studies of breast lymphoma, involving more than 100 patients, were from the International Extranodal Lymphoma Study Group (IELSG) (204 cases), ${ }^{5}$ Japan (380 cases), and Oklahoma College of Medicine 
Table 5 Multivariate analysis of prognostic factors for OS, PFS, LC, and CSS

\begin{tabular}{|c|c|c|c|}
\hline Variables & $\begin{array}{l}\text { Hazard } \\
\text { ratio }\end{array}$ & $95 \% \mathrm{Cl}$ & $P$-value \\
\hline \multicolumn{4}{|l|}{ os } \\
\hline \multicolumn{4}{|l|}{ Local/extended staging } \\
\hline Local & 1 & & \\
\hline Extended & 3.919 & $1.462-10.499$ & 0.007 \\
\hline \multicolumn{4}{|l|}{ Cycles of chemotherapy } \\
\hline$<4$ cycles & 1 & & \\
\hline$\geq 4$ cycles & 0.359 & $0.166-0.788$ & 0.009 \\
\hline \multicolumn{4}{|l|}{ IPI } \\
\hline Low to low intermediate & 1 & & \\
\hline High intermediate to high & 1.674 & $1.077-2.601$ & 0.022 \\
\hline \multicolumn{4}{|c|}{ Lumpectomy $\pm \mathrm{ALN}$ dissection } \\
\hline No & 1 & & \\
\hline Yes & 0.183 & $0.053-0.631$ & 0.007 \\
\hline \multicolumn{4}{|l|}{ PFS } \\
\hline \multicolumn{4}{|l|}{ Tumor size } \\
\hline$\leq 4 \mathrm{~cm}$ & 1 & & \\
\hline$>4 \mathrm{~cm}$ & 2.664 & $1.310-5.418$ & 0.007 \\
\hline \multicolumn{4}{|l|}{ B symptoms } \\
\hline No & I & & \\
\hline Yes & 5.274 & $1.805-15.410$ & 0.002 \\
\hline \multicolumn{4}{|l|}{ Rituximab use } \\
\hline Yes & 1 & & \\
\hline No & 4.355 & $1.698-11.173$ & 0.002 \\
\hline \multicolumn{4}{|l|}{ LC } \\
\hline \multicolumn{4}{|l|}{ Cycles of chemotherapy } \\
\hline$<4$ cycles & 1 & & \\
\hline$\geq 4$ cycles & 0.325 & $0.131-0.805$ & 0.015 \\
\hline \multicolumn{4}{|l|}{ Tumor size } \\
\hline$\leq 4 \mathrm{~cm}$ & I & & \\
\hline$>4 \mathrm{~cm}$ & 2.904 & $1.094-7.710$ & 0.032 \\
\hline \multicolumn{4}{|l|}{ Rituximab use } \\
\hline Yes & 1 & & \\
\hline No & 4.593 & $1.059-19.930$ & 0.042 \\
\hline \multicolumn{4}{|l|}{ css } \\
\hline \multicolumn{4}{|l|}{ Tumor size } \\
\hline$\leq 4 \mathrm{~cm}$ & 1 & & \\
\hline$>4 \mathrm{~cm}$ & 3.194 & $1.265-8.065$ & 0.014 \\
\hline \multicolumn{4}{|l|}{ ECOG performance status } \\
\hline $0-1$ & I & & \\
\hline $2-4$ & 3.228 & $1.273-8.187$ & 0.014 \\
\hline \multicolumn{4}{|l|}{ Local/extended staging } \\
\hline Local & 1 & & \\
\hline Extended & 6.117 & $2.263-16.532$ & $<0.001$ \\
\hline \multicolumn{4}{|l|}{ Cycles of chemotherapy } \\
\hline$<4$ cycles & I & & \\
\hline$\geq 4$ cycles & 0.377 & $0.164-0.865$ & 0.021 \\
\hline
\end{tabular}

Abbreviations: OS, overall survival; PFS, progression-free survival; $\mathrm{Cl}$, confidence interval; IPI, International Prognostic Index; ALN, axillary lymph node; LC, local control; CSS, cause-specific survival; ECOG, Eastern Cooperative Oncology Group.

(465 cases), ${ }^{12,13}$ all of which comprised multiple pathological subtypes in the prerituximab era. The conclusions were contradictory, and different treatments were recommended. Our study is a retrospective study but focuses solely on breast DLBCL.
Breast lymphoma is categorized as PBL or SBL. The definition of PBL was first proposed by Wiseman and $\mathrm{Liao}^{3}$ in 1972, and it only included patients with lymphoma involvement of the breast with or without regional lymph node (ipsilateral axillary and supraclavicular lymph node region). Patients who did not fit this definition were considered stage SBL. This definition criterion has many limitations because it was developed from a retrospective study of just 31 patients, and only 16 of these were PBL. Yhim et $\mathrm{al}^{6}$ attempted to divide breast lymphoma into OED and MED according to the number of extranodal organs involved. The study showed that instead of Ann Arbor traditional staging criteria, OED/ MED criteria were an independent prognostic factor in multivariate analysis. Staging of bilateral extranodal disease is challenging for Ann Arbor staging criteria. One can group it into $\mathrm{I}_{\mathrm{E}}$ (biclonal with bilateral disease), $\mathrm{IV}_{\mathrm{E}}$ (monoclonal with hematogenous dissemination), or $\mathrm{II}_{\mathrm{E}}$ (bilateral disease located on the same side of the diaphragm). In retrospective studies, the bilateral extranodal disease of paired organs such as adrenals and eyes always had a poor prognosis, ${ }^{14,15}$ whereas the testes, lungs, and salivary glands had a relatively good prognosis. ${ }^{16-18}$ The largest study of PBL classified it as PBL IV $\mathrm{E}_{\mathrm{E}}$, whereas others staged it as PBL $\mathrm{I}_{\mathrm{E}}$ or $\mathrm{II}_{\mathrm{E}}{ }^{5,19,20} \mathrm{In}$ our study, according to Ann Arbor staging, we found that

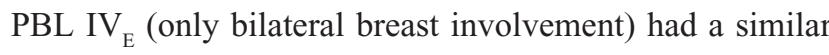
prognosis to SBL, and this was significantly worse than PBL $\mathrm{I}_{\mathrm{E}}$ and $\mathrm{II}_{\mathrm{E}}$. There was no significant statistical difference between PBL $\mathrm{I}_{\mathrm{E}}$ and $\mathrm{II}_{\mathrm{E}}$. As there is no direct connection between the two breasts, the bilateral involvement may indicate hematogenous dissemination. For this reason, we redefined breast lymphoma as local group (PBL $\mathrm{I}_{\mathrm{E}}$ and $\mathrm{II}_{\mathrm{E}}$ ) and extended group (PBL IV $\mathrm{IV}_{\mathrm{E}}$ and SBL). Although the three staging criteria all showed statistically significant difference in the univariate analysis, only the local/extended staging criterion was an independent prognostic factor for OS and CSS in the multivariate analysis. Both the former criteria (Ann Arbor stage and OED/MED stage) lost significance in the multivariate analysis. Therefore, we recommend local/ extended staging criteria as a better reflection of the difference of treatment outcome and prognosis.

The main symptom of breast lymphoma is a painless breast mass, which is indistinguishable from breast carcinoma; so the initial treatment for most patients remains surgery. Jennings et $\mathrm{l}^{13}$ found that 156 out of 465 patients underwent mastectomy, which decreased OS in a marginal trend $(P=0.055)$. The IELSG study revealed that radical mastectomy was an adverse factor for CSS in multivariate analysis $(\mathrm{HR}=2.4 ; P=0.03) .{ }^{5}$ Strikingly, our results reveal 
Table 6 Univariate analysis of local group (log-rank test)

\begin{tabular}{|c|c|c|c|c|c|c|c|c|c|}
\hline Variables & $\mathbf{n}$ & $5 y$ OS & $P$-value & 5y PFS & $P$-value & $5 y$ LC & $P$-value & 5y CSS & $P$-value \\
\hline All patients & 101 & 0.706 & & 0.616 & & 0.763 & & 0.817 & \\
\hline \multicolumn{10}{|l|}{ Sex } \\
\hline Male & 5 & 0.400 & 0.353 & 0.267 & 0.176 & 0.533 & 0.295 & 0.400 & 0.236 \\
\hline Female & 96 & 0.797 & & 0.634 & & 0.776 & & $0.84 I$ & \\
\hline \multicolumn{10}{|l|}{$\mathrm{LDH}$} \\
\hline Normal & 73 & 0.797 & 0.051 & 0.680 & 0.008 & 0.808 & 0.066 & 0.855 & 0.041 \\
\hline Elevated & 28 & 0.706 & & 0.408 & & 0.628 & & 0.706 & \\
\hline \multicolumn{10}{|l|}{ Age, years } \\
\hline$<60$ & 49 & 0.834 & 0.563 & 0.638 & 0.389 & 0.768 & $0.44 I$ & 0.865 & 0.815 \\
\hline$\geq 60$ & 52 & 0.701 & & 0.598 & & 0.766 & & 0.760 & \\
\hline \multicolumn{10}{|c|}{ ECOG performance status } \\
\hline $0-1$ & 96 & 0.786 & 0.016 & 0.637 & 0.164 & 0.763 & 0.889 & 0.829 & 0.006 \\
\hline $2-4$ & 5 & 0.600 & & 0.375 & & 0.750 & & 0.600 & \\
\hline \multicolumn{10}{|l|}{ B symptoms } \\
\hline Yes & 4 & 0.750 & 0.212 & 0.500 & 0.032 & 0.500 & 0.054 & 0.750 & 0.148 \\
\hline No & 97 & 0.776 & & 0.622 & & 0.755 & & 0.819 & \\
\hline \multicolumn{10}{|l|}{ Primary site } \\
\hline Left breast & 55 & 0.732 & 0.095 & 0.606 & 0.988 & 0.810 & 0.435 & 0.818 & 0.141 \\
\hline Right breast & 46 & 0.820 & & 0.617 & & 0.703 & & 0.820 & \\
\hline \multicolumn{10}{|l|}{ Primary tumor size } \\
\hline$\leq 4 \mathrm{~cm}$ & 54 & 0.785 & 0.086 & 0.727 & 0.004 & 0.866 & 0.010 & 0.866 & 0.048 \\
\hline$>4 \mathrm{~cm}$ & 47 & 0.748 & & 0.475 & & 0.643 & & 0.748 & \\
\hline \multicolumn{10}{|l|}{ IPI } \\
\hline Low & 81 & 0.770 & 0.067 & 0.624 & 0.938 & 0.766 & 0.918 & 0.817 & 0.040 \\
\hline Low intermediate & 17 & 0.863 & & 0.478 & & 0.695 & & 0.863 & \\
\hline High intermediate & I & & & & & & & & \\
\hline High & 2 & 0.500 & & & & & & 0.500 & \\
\hline \multicolumn{10}{|c|}{ Lumpectomy \pm ALN dissection } \\
\hline Yes & 34 & 0.963 & 0.003 & 0.728 & 0.062 & $0.84 I$ & 0.112 & 0.917 & 0.011 \\
\hline No & 67 & 0.689 & & 0.564 & & 0.723 & & 0.729 & \\
\hline \multicolumn{10}{|l|}{ Rituximab use } \\
\hline Yes & 35 & 0.795 & 0.204 & 0.843 & 0.007 & 0.915 & 0.014 & 0.883 & 0.138 \\
\hline No & 63 & 0.760 & & 0.506 & & 0.699 & & 0.786 & \\
\hline \multicolumn{10}{|l|}{ Local radiotherapy } \\
\hline Yes & 34 & 0.821 & 0.668 & 0.708 & 0.275 & 0.773 & 0.551 & 0.867 & 0.658 \\
\hline No & 67 & 0.793 & & 0.569 & & $0.76 \mathrm{I}$ & & 0.793 & \\
\hline \multicolumn{10}{|c|}{ Cycles of chemotherapy } \\
\hline$<4$ cycles & 23 & 0.595 & 0.015 & 0.499 & 0.120 & $0.56 \mathrm{I}$ & 0.007 & 0.595 & 0.017 \\
\hline$\geq 4$ cycles & 75 & 0.842 & & 0.658 & & 0.830 & & 0.894 & \\
\hline
\end{tabular}

Abbreviations: OS, overall survival; PFS, progression-free survival; LC, local control; CSS, cause-specific survival; LDH, lactate dehydrogenase; ECOG, Eastern Cooperative Oncology Group; IPI, International Prognostic Index; ALN, axillary lymph node.
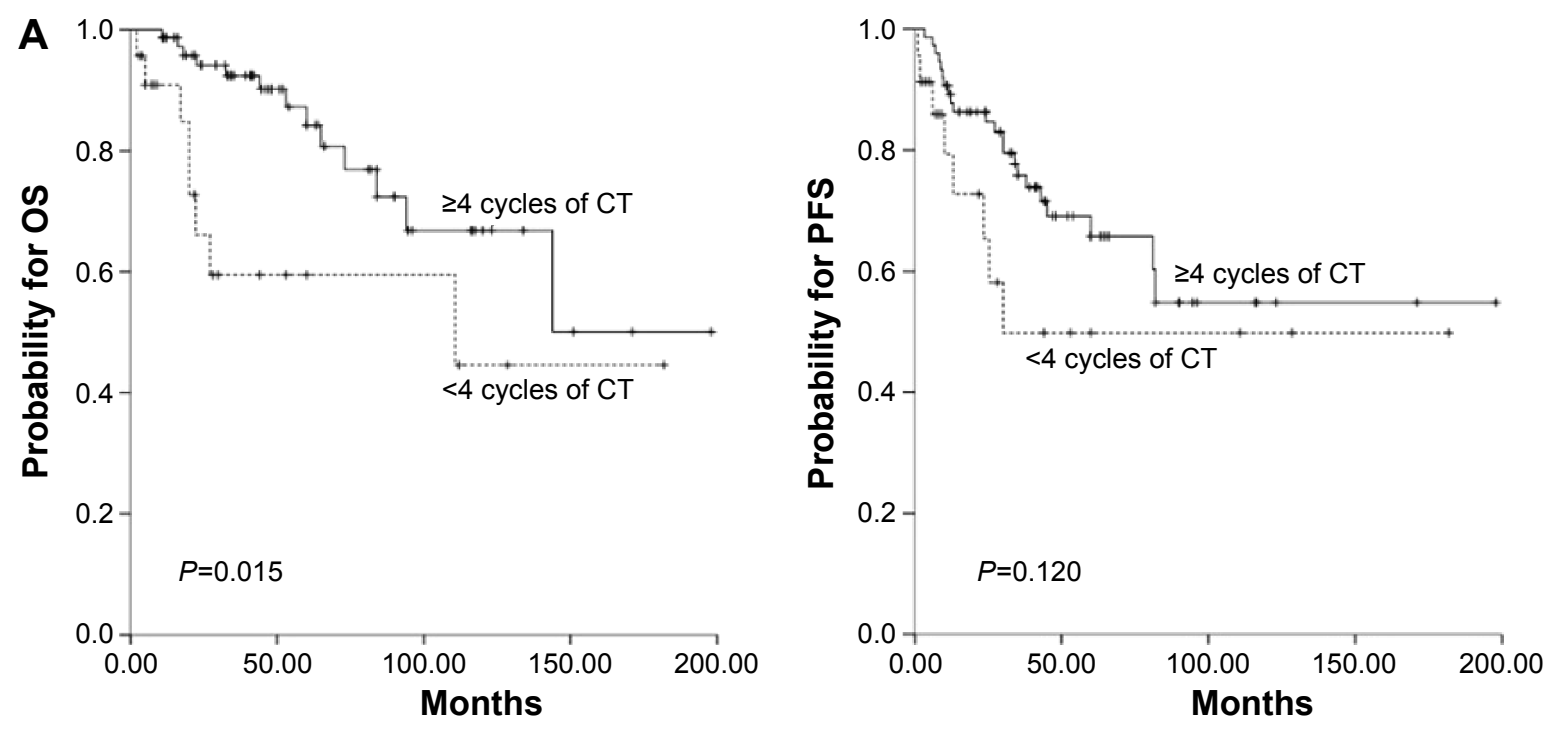

Figure 2 (Continued) 

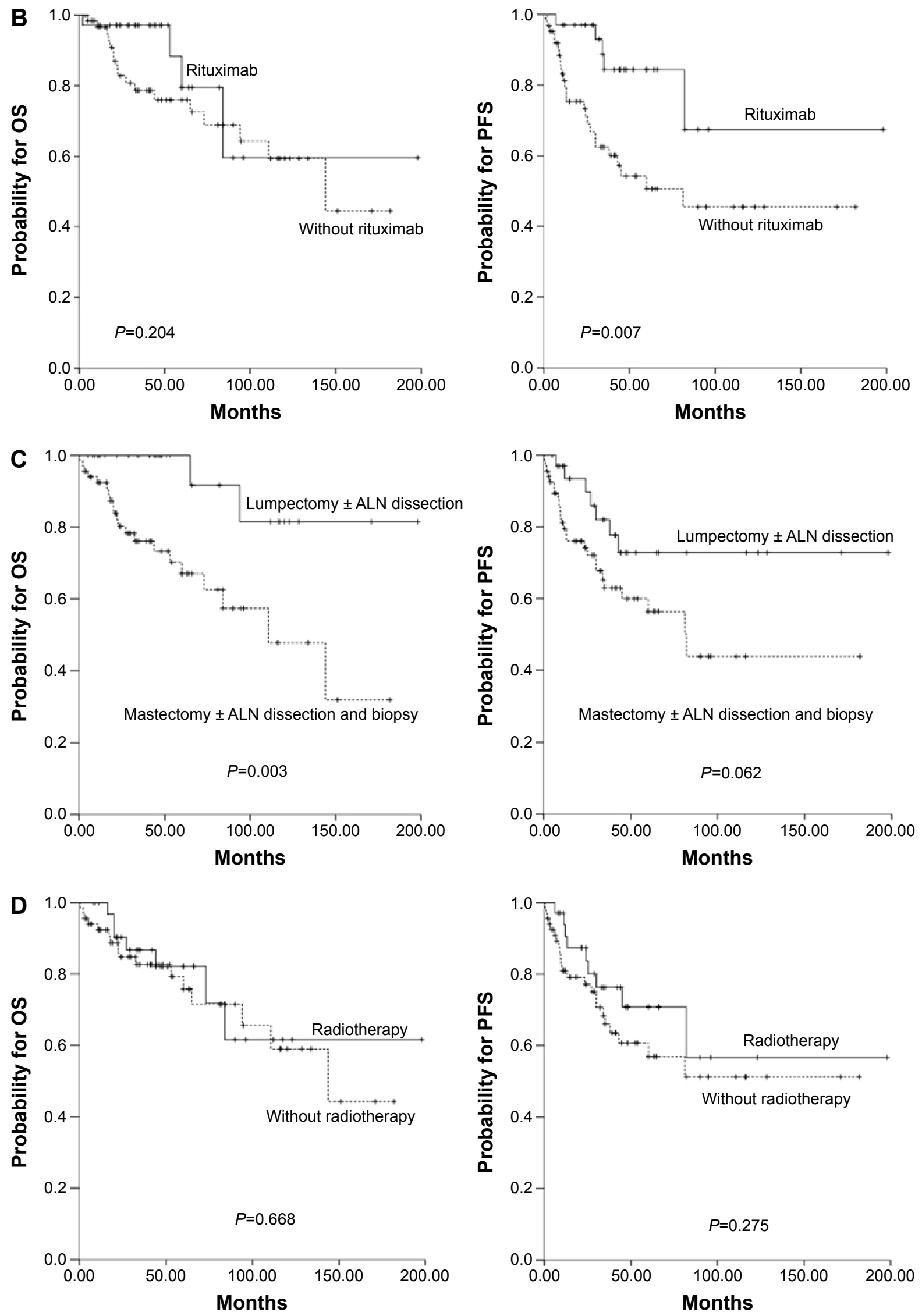

Figure 2 Survival curves for OS (left) and PFS (right) of each type of treatment in local group.

Notes: (A) Cycles of CT ( $\geq 4$ or $<4$ ); (B) the use of rituximab; (C) different surgical interventions (lumpectomy \pm ALN dissection or not); (D) the use of radiotherapy. Abbreviations: OS, overall survival; PFS, progression-free survival; CT, chemotherapy; ALN, axillary lymph node. 
Table 7 Multivariate analysis of local group

\begin{tabular}{|c|c|c|c|}
\hline Variables & Hazard ratio & $95 \% \mathrm{Cl}$ & P-value \\
\hline \multicolumn{4}{|l|}{ os } \\
\hline \multicolumn{4}{|c|}{ Cycles of chemotherapy } \\
\hline$<4$ cycles & 1 & & \\
\hline$\geq 4$ cycles & 0.353 & $0.144-0.865$ & 0.023 \\
\hline \multicolumn{4}{|c|}{ Lumpectomy \pm ALN dissection } \\
\hline No & $\mathrm{I}$ & & \\
\hline Yes & 0.164 & $0.038-0.707$ & 0.015 \\
\hline \multicolumn{4}{|l|}{ PFS } \\
\hline \multicolumn{4}{|l|}{ Tumor size } \\
\hline$\leq 4 \mathrm{~cm}$ & 1 & & \\
\hline$>4 \mathrm{~cm}$ & 2.806 & $1.306-6.025$ & 0.008 \\
\hline \multicolumn{4}{|l|}{ Rituximab use } \\
\hline Yes & 1 & & \\
\hline No & 3.311 & $1.264-8.673$ & 0.015 \\
\hline \multicolumn{4}{|l|}{ LC } \\
\hline \multicolumn{4}{|l|}{ Tumor size } \\
\hline$\leq 4 \mathrm{~cm}$ & 1 & & \\
\hline$>4 \mathrm{~cm}$ & 3.090 & I.085-8.806 & 0.035 \\
\hline \multicolumn{4}{|c|}{ Rituximab use } \\
\hline Yes & 1 & & \\
\hline No & 4.477 & $1.024-19.570$ & 0.046 \\
\hline \multicolumn{4}{|l|}{ css } \\
\hline \multicolumn{4}{|c|}{ ECOG performance status } \\
\hline $0-1$ & 1 & & \\
\hline $2-4$ & 4.694 & $1.508-14.612$ & 0.008 \\
\hline \multicolumn{4}{|c|}{ Cycles of chemotherapy } \\
\hline$<4$ cycles & 1 & & \\
\hline$\geq 4$ cycles & 0.333 & $0.127-0.875$ & 0.026 \\
\hline
\end{tabular}

Abbreviations: $\mathrm{Cl}$, confidence interval; OS, overall survival; $\mathrm{ALN}$, axillary lymph node; PFS, progression-free survival; LC, local control; CSS, cause-specific survival; ECOG, Eastern Cooperative Oncology Group.

that lumpectomy with or without ALN dissection was associated with a better 5-year OS, PFS, and CSS in the univariate analysis compared with mastectomy with or without ALN dissection and biopsy. In multivariate analysis, lumpectomy with or without ALN dissection was a favorable factor for 5 -year OS, both in the whole cohort and the local group. The reason for better prognosis of lumpectomy may be attributed to the decreasing of tumor load without the severe side effects of mastectomy. We recommend that surgical intervention should be limited to lumpectomy with or without ALN dissection, because this can also provide adequate specimens for pathological and immunohistological analysis.

The addition of rituximab to the CHOP regimen improved the survival of aggressive nodal DLBCL. ${ }^{10,11}$ However, the role of rituximab in patients with breast lymphoma has never been investigated thoroughly. The three largest retrospective studies of PBL only included patients who had undergone older therapeutic regimens, during which rituximab was not in extensive clinical use. The results were disappointing. ${ }^{5,12,13}$
In our study, $32.7 \%$ of the patients received rituximab and a standard chemotherapy regimen. In the univariate analysis, rituximab use was significantly associated with a superior 5-year PFS, LC, and CSS. It also remained significant for PFS and LC in multivariate analysis, for both the whole cohort and the local group. Another retrospective study including 31 patients also found that the patients with RCHOP use had a significantly better 5-year OS compared with patients undergoing the CHOP regimen alone $(82.4 \%$ vs $67.5 \%$; $P=0.038) .{ }^{19}$ Recently, a PBL and nodal DLBCL 1:3-matched retrospective study with RCHOP and involved field RT revealed that the OS was not significantly different between the two groups. The author suggested that the treatment outcomes of PBL were no longer inferior to those of nodal DLBCL in the rituximab era because it may change the poor prognosis of nongerminal center (GC) phenotype in PBL. ${ }^{21}$ The only prospective study investigating the role of rituximab for PBL enrolled 32 patients. It was a single focus study on the R-CEOP-14 regimen. The 3-year EFS and OS were $75 \%$ and $63 \%$, respectively, which was comparable to patients with CHOP regimen in the previous retrospective study. ${ }^{22}$ However, the CNS relapse rate in this study was much lower than that in another prospective CHOP-21 regimen study by the same author (CNS relapse rate: $0 \%$ vs $11 \%) .{ }^{4}$ The author attributed the difference to the intensive chemotherapy regimen CEOP-14. The CISL study also found no effect of rituximab on OS and PFS in patients with breast lymphoma. However, in this study, most patients with rituximab were at high risk, which may have masked its therapeutic effect. ${ }^{6}$ Even though rituximab appears to have great success in aggressive nodal DLBCL, future prospective studies are needed to prove its role for patients with breast DLBCL.

There is no standard treatment regimen for breast DLBCL. Most studies recommend limited surgery, more than four cycles of systemic chemotherapy, and local RT as the standard therapy. ${ }^{1,9}$ Our results revealed that more than four cycles of systemic chemotherapy were a favorable factor for survival. However, we have not found significant outcome improvements associated with local RT, which differs from some retrospective studies of PBL. Jennings et $\mathrm{al}^{13}$ found that RT had a trend of improving OS, especially for stage $\mathrm{I}_{\mathrm{E}}$ PBL (47.9\% vs $\left.37.1 \% ; P=0.07\right)$. The IELSG study also found that RT improved OS significantly in multivariate analysis $(\mathrm{HR}=0.5 ; 95 \% \mathrm{CI}=0.3-1.0 ; P=0.03) .{ }^{5}$ The only controlled, randomized prospective study of PBL revealed that systemic chemotherapy plus local RT was associated with a significantly better 5-year OS and EFS compared with the 
single-regimen group. ${ }^{4}$ However, the previously mentioned studies all focused on different pathological subtypes and scarce use of rituximab. In our study, the most common local relapse site was the contralateral breast (42.9\%). RT substantially decreased the risk of ipsilateral progression (HR RT: no $\mathrm{RT}=0.470 ; P=0.340$ ). For this reason, further studies are needed to investigate the use of RT of the involved breast, or even the contralateral one, in the rituximab era.

The limitations of our study are as follows. First, it is a retrospective study with a relatively small number of patients, short follow-up time, heterogeneity of patients from our institution and literature, and the inability to control for all factors influencing clinical outcomes. IPI scores of most of our patients $(92 \%)$ were $\leq 2$, which may contribute to the good prognosis of our study subjects compared with subjects from other studies. ${ }^{5,6}$ The fact that there are only a few cases of bilateral breast involvement in our study may bias the statistical analysis. Another important limitation is that molecular phenotypes were not available. It is widely accepted that DLBCL can be subdivided into germinal center B-cell (GCB) and nongerminal center B-cell (non-GCB) using gene expression profiling and immunohistochemistry. The nonGCB subtype has a much poorer prognosis than GCB..$^{23-25}$ The addition of rituximab to CHOP-like chemotherapy seemed to eliminate the prognostic difference between the non-GCB and GCB groups of nodal DLBCL. ${ }^{26,27}$ Currently, only a few studies have investigated the subclassification of PB-DLBCL and have showed that the predominant subtype was nongerminal center phenotype. ${ }^{28-30}$ Future studies are awaited on the prognosis of different molecular phenotypes, which may guide the treatment option.

\section{Conclusion}

This study reveals that the new local/extended staging criteria can reflect the difference of treatment outcomes and prognosis compared to traditional Ann Arbor staging. Extensive radical surgery may be harmful and may need to be avoided, hence our suggestion for limiting surgery to lumpectomy. The full course of anthracycline chemotherapy still appears to be an important treatment regimen for breast DLBCL. As there was improvement of PFS and $\mathrm{LC}$ in the rituximab group, both in the whole cohort and local group, this chemoimmunotherapy is recommended for breast DLBCL. Further prospective studies are warranted to investigate the role of RT in the rituximab era, using our new staging criteria.

\section{Disclosure}

The authors report no conflicts of interest in this work.

\section{References}

1. Aviv A, Tadmor T, Polliack A. Primary diffuse large B-cell lymphoma of the breast: looking at pathogenesis, clinical issues and therapeutic options. Ann Oncol. 2013;24(9):2236-2244.

2. Surov A, Holzhausen HJ, Wienke A, et al. Primary and secondary breast lymphoma: prevalence, clinical signs and radiological features. Br J Radiol. 2012;85(1014):e195-e205.

3. Wiseman C, Liao KT. Primary lymphoma of the breast. Cancer. 1972; 29(6):1705-1712.

4. Avilés A, Delgado S, Nambo MJ, Neri N, Murillo E, Cleto S. Primary breast lymphoma: results of a controlled clinical trial. Oncology. 2005;69(3): 256-260.

5. Ryan G, Martinelli G, Kuper-Hommel M, et al. Primary diffuse large B-cell lymphoma of the breast: prognostic factors and outcomes of a study by the International Extranodal Lymphoma Study Group. Ann Oncol. 2008;19(2):233-241.

6. Yhim HY, Kang HJ, Choi YH, et al. Clinical outcomes and prognostic factors in patients with breast diffuse large B cell lymphoma; Consortium for Improving Survival of Lymphoma (CISL) study. BMC Cancer. 2010;10:321.

7. Peto R, Pike MC, Armitage P, et al. Design and analysis of randomized clinical trials requiring prolonged observations of each patient. Introduction and design. Br J Cancer. 1976;34(6):585-612.

8. Cox DR. Regression models and life tables. J Roy Stat Soc. 1972;34(2): 187-220.

9. Cheah CY, Campbell BA, Seymour JF. Primary breast lymphoma Cancer Treat Rev. 2014;40(8):900-908.

10. Coiffier B, Lepage E, Briere J, et al. CHOP chemotherapy plus rituximab compared with CHOP alone in elderly patients with diffuse large-B-cell lymphoma. N Engl J Med. 2002;346(4):235-242.

11. Pfreundschuh M, Trümper L, Osterborg A, et al. CHOP-like chemotherapy plus rituximab versus CHOP-like chemotherapy alone in young patients with good-prognosis diffuse large-B-cell lymphoma: a randomised controlled trial by the MabThera International Trial (MInT) Group. Lancet Oncol. 2006;7(5):379-391.

12. Uesato M, Miyazawa Y, Gunji Y, Ochiai T. Primary non-Hodgkin's lymphoma of the breast: report of a case with special reference to 380 cases in the Japanese literature. Breast Cancer. 2005;12(2):154-158.

13. Jennings WC, Baker RS, Murray SS, et al. Primary breast lymphoma: the role of mastectomy and the importance of lymph node status. Ann Surg. 2007;245(5):784-789.

14. Salvatore JR, Ross RS. Primary bilateral adrenal lymphoma. Leuk Lymphoma. 1999;34:111-117.

15. Hoffman PM, McKelvie P, Hall AJ, Stawell RJ, Santamaria JD. Intraocular lymphoma: a series of 14 patients with clinicopathological features and treatment outcomes. Eye. 2003;17(4):513-521.

16. Kojima M, Shimizu K, Nishikawa M, et al. Primary salivary gland lymphoma among Japanese: a clinicopathological study of 30 cases. Leuk Lymphoma. 2007;48(9):1793-1798.

17. Cheah CY, Wirth A, Seymour JF. Primary testicular lymphoma. Blood. 2014;123(4):486-493.

18. Cordier JF, Chailleux E, Lauque D, et al. Primary pulmonary lymphomas. A clinical study of 70 cases in nonimmunocompromised patients. Chest. 1993;103(1):201-208.

19. Zhao S, Zhang QY, Ma WJ, et al. Analysis of 31 cases of primary breast lymphoma: the effect of nodal involvement and microvascular density. Clin Lymphoma Myeloma Leuk. 2011;11(1):33-37.

20. Fukuhara S, Watanabe T, Munakata W, et al. Bulky disease has an impact on outcomes in primary diffuse large B-cell lymphoma of the breast: a retrospective analysis at a single institution. Eur J Haematol. 2011;87(5):434-440.

21. Yhim HY, Kim JS, Kang HJ, et al. Matched-pair analysis comparing the outcomes of primary breast and nodal diffuse large B-cell lymphoma in patients treated with rituximab plus chemotherapy. Int J Cancer. 2012; 131(1):235-243.

22. Avilés A, Castaneda C, Neri N, Cleto S, Nambo MJ. Rituximab and dose dense chemotherapy in primary breast lymphoma. Haematologica. 2007;92(8):1147-1148. 
23. Rosenwald A, Wright G, Chan WC, et al. The use of molecular profiling to predict survival after chemotherapy for diffuse large-B-cell lymphoma. N Engl J Med. 2002;346(25):1937-1947.

24. Lenz G, Wright G, Dave SS, et al. Stromal gene signatures in large-Bcell lymphomas. N Engl J Med. 2008;359(22):2313-2323.

25. Hans CP, Weisenburger DD, Greiner TC, et al. Confirmation of the molecular classification of diffuse large B-cell lymphoma by immunohistochemistry using a tissue microarray. Blood. 2004;103:275-282.

26. Nyman H, Adde M, Karjalainen-Lindsberg ML, et al. Prognostic impact of immunohistochemically defined germinal center phenotype in diffuse large B-cell lymphoma patients treated with immunochemotherapy. Blood. 2007;109(11):4930-4935.

27. Winter JN, Weller EA, Horning SJ, et al. Prognostic significance of Bcl-6 protein expression in DLBCL treated with CHOP or R-CHOP: a prospective correlative study. Blood. 2006;107(11):4207-4213.

28. Aviles A, Neri N, Nambo MJ. The role of genotype in 104 cases of diffuse large B-cell lymphoma primary of breast. Am J Clin Oncol. 2012; 35(2):126-129.

29. Talwalkar SS, Miranda RN, Valbuena JR, Routbort MJ, Martin AW, Medeiros LJ. Lymphomas involving the breast: a study of 106 cases comparing localized and disseminated neoplasms. Am J Surg Pathol. 2008;32(9):1299-1309.

30. Niitsu N, Okamoto M, Nakamine H, Hirano M. Clinicopathologic features and treatment outcome of primary breast diffuse large B-cell lymphoma. Leuk Res. 2008;32(12):1837-1841.

31. Duan MH, Cao X, Cai H, et al. Clinical analysis of 14 cases with primary breast lymphoma. Zhonghua Xue Ye Xue Za Zhi. 2014;35(10):918-921. Chinese.

32. Inic Z, Inic M, Zegarac M, Inic I, Pupic G. Three cases of combined therapy in primary breast lymphoma (PBL) with successful outcomes. Clin Med Insights Oncol. 2013;7:159-163.
33. Jung SP, Kim M, Han KM, et al. Primary breast lymphoma: a single institution's experience. J Korean Surg Soc. 2013;84(5):267-272.

34. Mouna B, Saber B, Tijani el H, Hind M, Amina T, Hassan E. Primary malignant non-Hodgkin lymphoma of the breast: a study of seven cases and literature review. World J Surg Oncol. 2012;10:151.

35. Joks M, Myśliwiec K, Lewandowski K. Primary breast lymphomareview of the literature and report of three cases. Arch Med Sci. 2011; 7(1):27-33

36. Julen O, Dellacasa I, Pelte MF, et al. Primary breast lymphomas. Rare Tumors. 2009;1(1):e14.

37. Sanguinetti A, Ragusa M, Lucchini R, et al. Primary breast lymphoma: case reports and review of the literature. G Chir. 2008;29(5): 230-232.

38. Cabras MG, Amichetti M, Nagliati M, Orrù P, Mamusa AM, Angelucci E. Primary non-Hodgkin's lymphoma of the breast: a report of 11 cases. Haematologica. 2004;89(12):1527-1528.

39. Yoshida S, Nakamura N, Sasaki Y, et al. Primary breast diffuse large B-cell lymphoma shows a non-germinal center B-cell phenotype. Mod Pathol. 2005;18(3):398-405.

40. Seker M, Bilici A, Ustaalioglu BO, et al. Clinicopathologic features of the nine patients with primary diffuse large B cell lymphoma of the breast. Arch Gynecol Obstet. 2011;284(2):405-409.

41. Ogawa T, Tsuji E, Shirakawa K, et al. Primary non-Hodgkin's lymphoma of the breast treated nonsurgically: report of three cases. Breast Cancer. 2011;18(1):68-72.

42. Romero-Guadarrama MB, Hernández-González MM, DuránPadilla MA, Rivas-Vera S. Primary lymphomas of the breast: a report on 5 cases studied in a period of 5 years at the Hospital General de México. Ann Diagn Pathol. 2009;13(2):78-81.
OncoTargets and Therapy

\section{Publish your work in this journal}

OncoTargets and Therapy is an international, peer-reviewed, open access journal focusing on the pathological basis of all cancers, potential targets for therapy and treatment protocols employed to improve the management of cancer patients. The journal also focuses on the impact of management programs and new therapeutic agents and protocols on

\section{Dovepress}

patient perspectives such as quality of life, adherence and satisfaction The manuscript management system is completely online and includes a very quick and fair peer-review system, which is all easy to use. Visit http://www.dovepress.com/testimonials.php to read real quotes from published authors. 